\title{
Women at Midlife: An Exploration of Chronological Age, Subjective Age, Wellness, and Life Satisfaction
}

\section{Suzanne Degges-White and Jane E. Myers}

\begin{abstract}
Women $(\mathrm{N}=224)$ between 35 and 65 years old participated in a study that examined the relationship among chronological age, subjective age, wellness, and life satisfaction. Women whose subjective age was less than or equal to their chronological age reported greater wellness; total wellness was a significant predictor of life satisfaction.
\end{abstract}

Midlife is a fairly recently defined construct, due in part to the increased life expectancy in the United States, and it remains the most poorly understood period of the life span (Lachman, 2001). Often negatively associated with a major life crisis (Levinson \& Levinson, 1996; Wethington, Kessler, \& Pixley, 2004), midlife has also been described as a period of psychological awakening and significant inner development (Brehoney, 1996; Sheehy, 2006) and a time during which individuals may begin to direct their energy into generative pursuits (Erikson, 1968). These conflicting views indicate that there may be specific factors that influence an individual's passage through midlife in positive and negative ways, ultimately affecting life satisfaction and well-being (Steverink, Westerhof, Bode, \& Dittmann-Kohli, 2001); in addition, these factors may differ by gender (Howell, 2001; McQuaide, 1998).

Women who are 40 years old and over account for approximately $45 \%$ of the total U.S. female population (U.S. Bureau of the Census, 2001); however, theories of adult development have often failed to fully address the unique experiences of these women. Often, midlife women are victims of stereotypes that depict them as unhappy, unfulfilled, and stagnant (Howell, 2001). Further, the transitions commonly associated with midlife women are those of loss and physical decline (e.g., widowhood, empty nest, menopausal symptoms). Midlife women have been viewed as being maladjusted, exhibiting lower lev-

Suzanne Degges-White, Counseling and Development, Purdue University Calumet; Jane E. Myers, Counseling and Educational Development, University of North Carolina at Greensboro. Correspondence concerning this article should be addressed to Suzanne Degges-White, Counseling and Development, Purdue University Calumet, 2200 169th Street, Hammond, IN, 46323 (e-mail: dwhites@calumet.purdue.edu).

(C) 2006 by the American Counseling Association. All rights reserved. 
els of well-being and higher levels of depression and risk of suicide than other populations, and struggling with physical decline in a society that values a feminine ideal of youth (Girard, 1993; Hasin, Goodwin, Stinson, \& Grant, 2005; Howell, 2001; Saucier, 2004; Waskel \& Phelps, 1995). Individually and collectively, these factors function to limit women's development across the adult life span. Studies of women's midlife experiences are needed to dispel these negative stereotypes and to inform both professionals and women themselves of the potential for positive growth in the midlife decades (McQuaide, 1998; Waskel \& Phelps, 1995). One factor that seems to affect both life satisfaction and wellness is perceived age.

Chronological age, or actual years of life, differs from self-perception of one's age, often termed cognitive age or subjective age, which may be a more useful predictor of successful psychological and physical aging of adults than chronological age (Uotinen, Rantanen, \& Suutama, 2005; Wilkes, 1992). Subjective age provides a better indicator of adults' views of their roles in society, which in turn yields a more accurate understanding of their behaviors and attitudes (Henderson, Goldsmith, \& Flynn, 1995). Palmore (1981) suggested that having a subjective age lower than one's chronological age would be positively associated with life satisfaction. The results of numerous studies have shown that adult women's subjective age tends to be significantly younger than their chronological age (Hummert, Garstka, O'Brien, Greenwald, \& Mellott, 2002). In fact, Montepare and Lachman (1989) determined that both subjective age and chronological age were significant predictors of life satisfaction. Barak and Stern (1986) noted that as women grow older, they increasingly define their subjective age as younger than their chronological age. This may be an instinctive or subconscious reaction to the finding that women and men both see old age beginning earlier for women than it does for men (Seccombe \& Ishii-Kuntz, 1991); it may also help to explain why women often feel compelled to maintain a youthful appearance to avoid the stigma of old age and to maintain a sense of well-being (Pinquart \& Sorensen, 2001; Saucier, 2004).

Multiple studies have revealed both age and gender differences in some aspects of well-being or holistic wellness (Dew \& Newton, 2005); however, there are few studies that focus on women who are in midlife and in the later stages of life (Myers, 2005). Rodin and Ickovics (1990) reported that women, especially during midlife, are diagnosed with mental disorders and prescribed psychotropic medications more frequently than men, and Hasin et al. (2005) found that middle-aged women were more likely to suffer from major depression. Although there have been no conclusive findings that gender determines subjective well-being (Diener, Suh, Lucas, \& Smith, 1999), "significant [gender] differences" exist in areas such as biological well-being and the diagnosis and treatment of physical and mental illness (Crose, Nicholas, Gobble, \& Frank, 1992, p. 151). Crose et al. suggested that gender differences, for example, the type of stressors faced, affect women's success in optimizing both 
their holistic wellness (Myers, Sweeney, \& Witmer, 2000) and their life satisfaction (Ryff \& Keyes, 1995).

Life satisfaction (i.e., a person's level of contentment with all aspects of her or his life) is the most widely studied variable in relation to successful aging and is strongly supported as a component of subjective well-being (McIntosh, 2001). Although early research has shown that youth is one of the most reliable predictors of life satisfaction (Wilson, 1967), recent studies have indicated that life satisfaction increases with age, at least in early adulthood from the 20 s to the late 30s (Hong \& Giannakopoulos, 1994). From age 40 onward, adulthood is a time of transition, intensified self-evaluation, and life assessment, processes that can affect life satisfaction (Ryff, 1989).

In summary, midlife women face significant challenges in achieving both wellness and life satisfaction, and factors such as subjective age may be important issues during this developmental period. Midlife is often accompanied by negative self-images and an increased risk for affective mood disorders. The relationship among factors such as subjective age, wellness, and life satisfaction as predictors of successful midlife adjustment merit further exploration as a foundation for better understanding the midlife experience of women.

The present study was undertaken to explore the nature of the contemporary woman's midlife experience, specifically the relationship among chronological age, subjective age, wellness, and life satisfaction. The following four hypotheses were examined:

1. There is a relationship between chronological age and subjective age for midlife women.

2. Women whose subjective age is younger than or equivalent to their chronological age will have higher mean levels of wellness than women whose subjective age is older than their chronological age.

3. Women whose subjective age is younger than their chronological age will report higher levels of life satisfaction.

4. The variance in life satisfaction can be accounted for by wellness and factors such as household income and education.

\section{METHODOLOGY}

Volunteers between the ages of 35 and 65 years were recruited through a variety of means. Notices were placed on electronic mailing lists that serve predominantly adult female memberships and on special interest electronic mail lists that include midlife women. Flyers were placed at women's centers and health organizations; snowball sampling was implemented by having participants contact other midlife women and inviting them to participate. Faceto-face recruitment was used at women's centers, classrooms, and church groups. 
The nature of the sampling procedures did not allow for an accurate response rate to be determined, nor was it possible to determine if the characteristics of the women who volunteered for the study differed in any meaningful ways from those who chose not to participate. Of 380 distributed questionnaires, 241 (63\%) were returned. Of these, 2 were excluded from the data analysis because the respondents did not meet the specified age criteria, 5 were incomplete, and 10 were received after the deadline for responses had passed.

\section{Participants}

The resulting sample of 224 participants, representing a response rate of $58.9 \%$ for distributed surveys, was a heterogeneous group of midlife women. Respondents aged $45-54$ years represented $43.3 \%$ of the sample, $38.8 \%$ were $35-44$ years old, and $17.9 \%$ of the respondents were $55-65$ years old. The mean age for respondents was 47.33 years $(S D=7.44)$. The majority of the respondents were Caucasian (85.7\%), 8.9\% were African American, 1.8\% were Native American/American Indian, $0.9 \%$ were Asian/Pacific Islander, and the remaining $2.7 \%$ marked other as their race. Approximately half (50.9\%) of the participants reported annual household incomes of less than $\$ 60,000$. Most of the participants $(65.2 \%)$ were married or partnered, $15.2 \%$ were single, and $14.3 \%$ were divorced. The majority (60.3\%) were employed full-time. A broad range of education levels were reported, with $30.1 \%$ of the participants having earned less than a bachelor's degree; $24.5 \%$ had earned a bachelor's degree, and $43 \%$ reported having received education beyond the bachelor's-degree level. The majority of respondents $(77.8 \%)$ were from the southeastern region of the United States.

\section{Instruments}

Participants completed three paper-and-pencil assessment instruments, including a Subjective Age Questionnaire (SAQ; Barak, 1987), the Five Factor Wellness Inventory (5F-Wel; Myers \& Sweeney, 1999, 2005), the Satisfaction With Life Survey (SWLS; Diener, Emmons, Larsen, \& Griffin, 1985), and a brief demographic questionnaire.

SAQ (Barak, 1987). The SAQ was designed to measure individuals' subjective age or self-perceived age in relation to four age-related concepts: feel age, activity age, interests age, and look age. The SAQ consists of four statements (e.g., "I feel like someone who is in their___") to which respondents choose one of eight age-decade responses (e.g., teens, 20s, 80s). SA is determined by averaging the responses to the four questions to generate a single continuous measure. Barak and Stern (1986) reported an internal consistency of .87 for the SAQ. In a recent study with adult women who were between 50 and 83 years old, Guiot (2001) used structural equation modeling to determine that subjective age was best defined when the look-age question was eliminated from the original four questions. Guiot reported a Cronbach's alpha of .93 from his study of 225 women when the look-age question was removed. Therefore, only the 
three non-appearance-based items were included in the current study. Our Cronbach's alpha was .77.

5F-Wel (Myers \& Sweeney, 1999, 2005). The 5F-Wel was developed to measure the factors of wellness that were identified in the Indivisible Self Model (Myers, 2005). The instrument includes 73 items that are behavioral and attitudinal statements (e.g., "I am an active person"). Responses are made using a 4-point, Likert-type scale, and scores are simple sums of items on each scale. A linear transformation places all scales on a common metric with a possible range of 25-100. Norms are reported for 474 men and 820 women (Myers \& Sweeney, 2005); the female norms were used in this study.

Exploratory and confirmatory factor analyses supported a single, higher order factor (Total Wellness), 5 second-order factors, and 17 discrete third-order factors (Hattie, Myers, \& Sweeney, 2004). Only the single Wellness factor was used in this study. This factor is measured with all 73 items, for which the authors reported a Cronbach's alpha of .94. The alpha in the current study was .92.

SWLS (Diener et al., 1985). The SWLS was designed to measure respondents' overall or global satisfaction with their lives. The SLWS is composed of five items (e.g., "In most ways my life is close to my ideal") which are rated on a 7-point scale, from 1 (strongly disagree) to 7 (strongly agree). Answers to the five items are averaged, yielding a single measure of global life satisfaction. The internal consistency of the five-item instrument has been supported by multiple studies in which both alpha and test-retest coefficients consistently exceeded .80 (Pavot \& Diener, 1993). The Cronbach's alpha was .84 for the current sample.

\section{Data Analyses}

Data were analyzed using SPSS 11.0.1, and an alpha of .05 was set for determining statistical significance. Descriptive statistics were calculated for all demographic variables and for scales of the instruments. Pearson product-moment correlation coefficients, multivariate analyses of variance, and regression analysis were used to examine the research questions.

\section{RESULTS}

In Table 1, the means; standard deviations; minimum and maximum values for chronological age and subjective age; and scores on the SAQ, the 5F-Wel, and the SWLS are presented. Norm group values for the 5F-Wel are included in the table note. Participants were divided into three groups on the basis of chronological age: 35-44 years, 45-54 years, and 55-65 years. The discrepancy between the mean chronological age and the mean subjective age became increasingly larger for each age group, and there was greater variability among the subjective and chronological ages.

In Table 2, means and standard deviations for participants' scores on the 5FWel and SWLS for subjective age-chronological age comparisons, as well as 


\section{TABLE 1}

Chronological and Subjective Age, Subjective Age Questionnaire (SAQ), Five Factor Wellness Inventory (5F-Wel), and Satisfaction With Life Survey (SWLS) Results

\begin{tabular}{|c|c|c|c|c|c|c|c|c|c|c|}
\hline \multirow{3}{*}{$\begin{array}{l}\text { Age } \\
\text { Instruments } \\
\text { and Scales }\end{array}$} & \multirow{2}{*}{\multicolumn{4}{|c|}{ Total Sample $(N=224)$}} & \multicolumn{6}{|c|}{ Three Age Groups } \\
\hline & & & & & \multicolumn{2}{|c|}{$\begin{array}{l}35-44 \\
(n=87)\end{array}$} & \multicolumn{2}{|c|}{$\begin{array}{c}45-54 \\
(n=97)\end{array}$} & \multicolumn{2}{|c|}{$\begin{array}{c}55-65 \\
(n=40)\end{array}$} \\
\hline & Min. & Max. & $M$ & $S D$ & $M$ & $S D$ & $M$ & $S D$ & $M$ & $S D$ \\
\hline $\begin{array}{l}\text { Chronological } \\
\text { Age }\end{array}$ & 35 & 65 & 47.33 & 7.44 & 39.95 & 2.97 & 49.12 & 2.73 & 59.00 & 3.11 \\
\hline Subjective & & & & & & & & & & \\
\hline $\begin{array}{l}\text { Age } \\
\text { SAQ }\end{array}$ & 25.00 & 68.33 & 40.12 & 7.10 & 36.69 & 6.39 & 40.74 & 5.83 & 46.08 & 7.15 \\
\hline $\begin{array}{l}\text { Feel Age } \\
\text { Interests }\end{array}$ & 25.00 & 65.00 & 39.46 & 8.51 & 35.11 & 6.90 & 40.88 & 7.33 & 45.50 & 9.59 \\
\hline $\begin{array}{c}\text { Age } \\
\text { Activity }\end{array}$ & 25.00 & 65.00 & 40.76 & 8.79 & 39.91 & 9.32 & 40.46 & 7.50 & 45.50 & 8.97 \\
\hline Age & 25.00 & 65.00 & 40.13 & 8.78 & 36.03 & 7.93 & 40.88 & 7.60 & 47.25 & 8.32 \\
\hline $5 \mathrm{~F}-\mathrm{Wel}^{\mathrm{a}}$ & 48.97 & 93.49 & 77.98 & 7.15 & 77.40 & 6.88 & 78.20 & 7.16 & 78.68 & 7.75 \\
\hline SWLS & 1.20 & 7.00 & 4.74 & 1.40 & 4.56 & 1.36 & 4.74 & 1.47 & 5.17 & 1.21 \\
\hline
\end{tabular}

aNorm group minimum score $=25 ;$ maximum $=100 ; M=76.55 ; S D=11.09$.

percentage responding for each age group, are provided. As shown in Table 2, each successive age group had an increasingly larger percentage of participants reporting a subjective age younger than their chronological age. Conversely, each successive age group had a decreasingly smaller number of participants reporting a subjective age older than their chronological age.

\section{The Relationship Between Chronological Age and Subjective Age}

A Pearson product-moment correlation calculated to test the first hypothesis revealed a significant, positive relationship between chronological age and sub-

\section{TABLE 2}

Five Factor Wellness Inventory (5F-Wel) and Satisfaction With Life Survey (SWLS) Results by Subjective Age-Chronological Age

\begin{tabular}{|c|c|c|c|c|c|c|c|}
\hline \multirow[b]{3}{*}{ SA Value } & \multicolumn{4}{|c|}{$\begin{array}{l}\text { Total Sample } \\
\qquad(N=224)\end{array}$} & \multicolumn{3}{|c|}{$\begin{array}{c}\% \text { Responding for Three Age } \\
\text { Groups }\end{array}$} \\
\hline & \multicolumn{2}{|c|}{$5 \mathrm{~F}-\mathrm{Wel}$} & \multicolumn{2}{|c|}{ SWLS } & \multirow{2}{*}{$\begin{array}{l}35-44 \\
(n=87)\end{array}$} & \multirow{2}{*}{$\begin{array}{c}45-54 \\
(n=97)\end{array}$} & \multirow{2}{*}{$\begin{array}{c}55-65 \\
(n=40)\end{array}$} \\
\hline & $M$ & $S D$ & $M$ & $S D$ & & & \\
\hline $\mathrm{SA}<\mathrm{CA}$ & 229.81 & 18.99 & 4.92 & 1.36 & 37.9 & 69.1 & 85.0 \\
\hline$S A=C A$ & 226.97 & 20.34 & 4.46 & 1.43 & 51.7 & 29.9 & 12.5 \\
\hline $\mathrm{SA}>\mathrm{CA}$ & 202.18 & 31.15 & 4.67 & 1.40 & 10.3 & 1.0 & 0.03 \\
\hline
\end{tabular}

Note. $\mathrm{SA}=$ subjective age; $\mathrm{CA}=$ chronological age . 
jective age $\left(r=.50, R^{2}=.25\right)$. There was a slightly larger statistically significant positive relationship between chronological age and the discrepancy value, or difference between chronological age and subjective age $(r=.54)$, accounting for just under one third of the variance in subjective age $\left(R^{2}=-.29\right)$. A significant negative relationship was found between subjective age and the discrepancy value $(r=-.47)$. These findings support the first hypothesis.

\section{Overall Wellness and Subjective Age}

A two-way analysis of variance (ANOVA) was conducted to test the second hypothesis (i.e., women whose subjective age is younger than or equivalent to their chronological age will have higher mean levels of wellness than women whose subjective age is older than their chronological age). A subjective agechronological age comparison value (see Table 2 ) was used as the independent variable, and overall wellness was used as the dependent variable. Chronological age and subjective age were significantly related to wellness $(F=9.572, d f=$ $2, p<.0001)$; however, caution is advised in interpreting this finding due to unequal sample sizes, which increases the probability of a Type I error (Scheffé, 1959). The partial eta ${ }^{2}$ calculation as a measure of effect size was .08, indicating that $8 \%$ of the variance in wellness scores was due to the chronologicalsubjective age relationship. Thus, the second hypothesis was supported.

\section{Life Satisfaction and Subjective Age}

The third hypothesis (i.e., women whose $\mathrm{SA}$ is younger than or equivalent to their chronological age will have higher mean levels of life satisfaction than women whose subjective age is older than their chronological age) was tested using a two-way ANOVA. The mean life satisfaction scores for participants, according to their subjective age comparison group, are shown in Table 2. The relationship between chronological age and subjective age was not significantly related to life satisfaction $(F=2.814, d f=2, p=.06)$; thus, the third hypothesis was not supported.

\section{Predictors of Life Satisfaction}

According to the fourth hypothesis, a significant amount of the variance in life satisfaction would be accounted for by level of wellness, level of household income, and level of education, each of which has been traditionally assumed to have an impact on life satisfaction (Diener, Suh, \& Oishi, 1997). To test this hypothesis, wellness, household income, and educational level were entered into a regression equation, and the standardized regression coefficients of the variables were analyzed to determine their predictive value regarding life satisfaction. The results indicated that these variables together accounted for $25 \%$ of the variance in life satisfaction, $R^{2}=.25, F=23.079(3,209), p<.000$, supporting the fourth hypothesis. Examination of the beta weights of the regression coefficients revealed that only wellness, $\beta=.378 t(3,209)=6.05$, 
$p=.0001$, and household income, $\beta=.240 t(3,209)=3.76, p=.0001$, explained a significant proportion of the variance in life satisfaction.

\section{DISCUSSION}

A study of 224 women, ages 35 to 65 years, was conducted to explore the relationship among chronological age, subjective age, wellness, and life satisfaction. Three of the four hypotheses were supported. Women with a subjective age less than or equal to their chronological age reported greater wellness, and total wellness was a significant predictor of life satisfaction. The discrepancy between chronological age and subjective age was not related to life satisfaction.

The statistically significant positive correlations between chronological age and subjective age and between chronological age and the discrepancy value indicated that women reported subjective age younger than their chronological age. This finding supports the existing literature (Hummert et al., 2002) and may reflect cultural messages regarding the need to maintain a youthful image and outlook, as described by Saucier (2004) and Pinquart and Sorenson (2001). However, an earlier study by Montepare and Lachman (1989) was unable to support a link between chronological age-subject age discrepancies and fears of aging for adult women. With each successive age group in the sample, an increasingly larger percentage of women reported subjective age younger than their chronological age. Few women reported subjective age greater than their chronological age, and the number decreased markedly with age. Further research is needed to verify and explain the meaning of the current findings, particularly why more than 1 in 10 of the youngest women reported their subjective age as older than their chronological age. How this finding was related to the midlife experience of these women and how their wellness and life satisfaction were affected remain to be determined.

The literature reviewed earlier suggested that a positive relationship exists between subjective age and wellness. The midlife women in this study who reported a subjective age that was younger than or equivalent to their chronological age also reported higher wellness. Although unequal cell sizes mandate caution in interpreting this particular result, the finding is interesting and merits further exploration. It will likely be difficult, based on the demographics of this sample, to generate equal cell sizes for this type of analysis. Perhaps qualitative methods will be required to elucidate the true meaning of wellness in relation to the subjective age-chronological age discrepancy. Similarly, lack of support for the hypothesis that women with a subjective age younger than or equivalent to their chronological would report higher life satisfaction may be due to the small sample size or to other factors that require further exploration.

Mounting evidence has supported the belief that life satisfaction increases with age (Hong \& Giannakopoulos, 1994). The current findings support this evidence, at least for chronological age. However, a similar linear relationship 
was not found for subjective age. The questions that assess life satisfaction focus on subjective feelings about current circumstances rather than on engagement in activities or behaviors. Perhaps the women who reported a younger subjective age were more dissatisfied with their lives and were attempting to make choices to improve their situations. Breytspraak (1984) found that the smaller the discrepancy between chronological age and subjective age, the greater one's life satisfaction; however, no similar relationship was found for this sample although a significant correlation between discrepancy value and wellness was revealed with smaller discrepancies related to higher levels of overall wellness.

Overall, the current findings support earlier research findings that youth and health are associated with satisfaction with life (Wilson, 1967). However, contrary to previous studies, level of education was not a significant predictor of life satisfaction. It is interesting to note that wellness is a significant predictor of life satisfaction, especially in light of the finding in this study that wellness is a construct that includes behaviors as well as attitudes and feelings. The midlife women in this study who engaged in healthpromoting activities and who had positive attitudes expressed greater life satisfaction than the women who did not engage in these behaviors. The fact that the second strongest significant predictor of life satisfaction was level of household income makes intuitive sense and parallels Fujita and Diener's (2005) recent finding that income was a variable that mirrored life satisfaction stability over time.

\section{LIMITATIONS}

A number of potential limitations may affect the internal and external validity of the current findings. The sample included selection bias in the form of selfselection, and although efforts were made to recruit women from as wide a demographic base as possible and one that was as geographically diverse as possible, the sample was not demographically representative of the overall population; participants were predominantly Caucasian and well-educated. Additional limitations arise from the overall sample size and specific group sizes used in the study analysis. Reliance on self-report measures is also a limitation of particular concern, due to the influences of social desirability, response biases, and lack of collaboration with other sources.

\section{IMPLICATIONS}

These findings have implications for counseling professionals in a variety of settings and provide valuable data that can help shape more appropriate mental health care and service programming for midlife women. We discuss the findings as they are related to counseling practice, counselor education, and future research. 


\section{Counseling Practice}

Cultural stereotypes of the midlife period suggest that women are seen as physically unattractive, barren, asexual, menopausal, depressed, irritable, frustrated, and intellectually dull (MacPherson, 1995; Markson \& Taylor, 2000). However, the women in this study suggested that midlife can be a time of satisfaction, wellness, and feeling younger than one's age. This new view of what midlife may mean for women requires counseling professionals to look at this period of life as one of growth, development, movement, and challenge. Typically, this period of life has been viewed as a time of introspection and evaluating one's life, and this may encourage women to make choices that would traditionally be ascribed to individuals who are chronologically younger. Service providers may want to assess women's self-perception of subjective age, rather than focusing on chronological age alone. Understanding the relationship that subjective age has with wellness and health-promoting behaviors may be important in working with midlife women who may feel unprepared to handle transitions that accompany aging.

Understanding that midlife is often a time of new developments, not necessarily a time of tying up loose ends, will enable counselors to normalize any dissatisfaction that women may experience during this developmental period. As the age norms for life events begin to blur and as longevity increases for today's adults, women who are now making choices that were once nontraditional may be confronted with opposition from family members or others who feel that their choices are inappropriate. By providing supportive and empowering counseling techniques, women may feel more competent to make changes in their lives that may lead to enhanced wellness and life satisfaction.

By using a counseling approach that is grounded in feminist theory and that is collaborative and empowering, counselors will be able to join with their midlife women clients in mutual goal setting that will invite women to identify their own needs and work toward the goals that they deem appropriate for themselves on the basis of their subjective age rather than their chronological age. When they empower their midlife clients, counselors affirm their clients' self-knowledge and enhance their ability to trust themselves on the basis of self-defined parameters of development and change, rather than those of traditional society.

Counseling professionals may be working with midlife women who are having difficulties filling new roles, including parent, caregiver, new wife or partner, newly single, or returning student. Counselors must take into account how women see themselves and their subjective ages and not focus entirely on their clients' chronological age. Understanding the relationship that subjective age has with wellness and health-promoting behaviors is important in working with midlife women who may feel overwhelmed at the transitions confronting them. By using a strengths-based approach and a wellness orientation, counselors can educate midlife clients about the importance of making choices that are appropriate for them as individuals. To help clients achieve optimal life 
satisfaction, it is important that their lifestyle be evaluated for factors that are conducive to enhanced wellness, whether they are handling multiple roles or exiting a long-term relationship. Counselors must be flexible in their views of life span development, put aside notions of what midlife women look like according to literature that is grounded in decades-old contexts, and collaborate with their clients to develop interventions that promote healthy behaviors and make sense for the client.

\section{Counselor Education}

For counselors to hold a more accurate view of the midlife developmental period, counselor educators must assess the representation of the midlife period that human development classes are providing as well as examine other core counseling classes that are training counselors to work with midlife women. It is important for counselors-in-training to be made aware that adult development continues well past the 18 th or 21 st year of life, that development does not stop abruptly, as some textbooks suggest. Other courses that should include specific attention to midlife include career counseling, student development course work, and family and couples counseling courses. Counselor educators should instill in their students a strengths-based wellness approach to working with midlife women, as well as all of their clients. For midlife women, there is a clear relationship between subjective age and wellness and between wellness and life satisfaction. Training counselors to take a holistic, wellnessbased perspective prepares them to be better able to help their midlife women clients grow toward optimal well-being and life satisfaction.

\section{Future Research}

Subjective age has been a part of marketing research for many years, yet the social sciences have not noticeably embraced this measure. Our finding that subjective age and wellness are significantly related supports the previously reported relationship among subjective age and attitudes and behaviors. Both constructs, subjective age and wellness, are predictors of attitudes and behaviors, and perhaps more research using the concept of subjective age, rather than chronological age, may enhance understanding of the aging process as it affects an individual's attitudes and feelings about her- or himself.

Further research is needed to better understand the psychological changes women experience as they enter the middle years of their lives because the majority of the research on midlife women is focused on physiological transitions (i.e., menopause). Considering the strong relationship found between wellness, income, and life satisfaction, it seems that more research on factors that contribute to the well-being of midlife women may provide more tangible clues to the factors affecting their satisfaction with life. Using a model like the Indivisible Self Model (Myers \& Sweeney, 2005) and examining all of the factors that comprise holistic wellness rather than just total wellness scores may be a fruitful avenue for future researchers. 


\section{CONCLUSION}

This study provided empirical evidence linking subjective age to wellness in one of the first studies to assess this relationship. Both subjective age and wellness are predictors of attitudes and behaviors, and perhaps more research using subjective age, rather than chronological age, may enhance understanding of the aging process as it affects one's attitudes and feelings about oneself. Future studies could explore the relationship between lifestyle and demographic variables other than income (e.g., ehtnicity, partnership status) that might affect wellness and life satisfaction, and focus more specifically on the components of wellness rather than on the construct as a global measure of well-being. Information from such studies could provide needed knowledge to help shape interventions to better equip women to make the most health-promoting choices throughout their lives. This study is notable in that it provides an updated exploration of contemporary women's midlife experience. The results provide evidence that linking subjective age to wellness is an important consideration. Findings support the value of a strengths-based, wellness-oriented approach for counseling midlife women based on the relationship we found between subjective age, wellness, and life satisfaction. By incorporating the knowledge derived from this study into their work, practitioners and service providers may be better prepared to assist their midlife clients move toward optimal wellness and life satisfaction.

\section{REFERENCES}

Barak, B. (1987). Cognitive age: A new multidimensional approach to measuring age identity. International Journal of Aging and Human Development, 25, 109-125.

Barak, B., \& Stern, B. (1986). Subjective age correlates: A research note. The Gerontologist, 26, $571-578$.

Brehoney, K. A. (1996). Awakening at midlife. New York: Riverhead Books.

Breytspraak, L. M. (1984). The development of self in later life. Boston: Little, Brown \& Co.

Crose, R., Nicholas, D. R., Gobble, D. C., \& Frank, B. (1992). Gender and wellness: A multidimensional systems model for counseling. Journal of Counseling \& Development, 71, 149-156.

Dew, B. J., \& Newton, K. (2005). Gender, sexual orientation, and wellness: Research implications. In J. E. Myers \& T. J. Sweeney (Eds.), Wellness in counseling: Theory, research, and practice (pp. 127-138). Alexandria, VA: American Counseling Association.

Diener, E., Emmons, R. A., Larsen, R. J., Griffin, S. (1985). The Satisfaction With Life Scale. Journal of Personality Assessment, 49, 71-75.

Diener, E., Suh, E. M., Lucas, R. E., \& Smith, H. (1999). Subjective well-being: Three decades of progress. Psychological Bulletin, 125, 276-302.

Diener, E., Suh, E., \& Oishi, S. (1997). Recent findings on subjective well-being. Indian Journal of Clinical Psychology, 24, 25-41.

Erikson, E. (1968). Identity, youth and crisis. New York: Norton.

Fujita, F., \& Diener, E. (2005). Life satisfaction set point: Stability and change. Journal of Personality and Social Psychology, 88, 158-164.

Girard, C. (1993). Age, gender, and suicide: A cross-national analysis. American Sociological Review, 58(4), $5553-5574$.

Guiot, D. (2001). Antecedents of subjective age biases among senior women. Psychology and Marketing, 18, 1049-1071. 
Hasin, D. S., Goodwin, R. D., Stinson, F. S., \& Grant, B. F. (2005). Epidemiology of major depressive disorder: Results from the National Epidemiologic Survey on Alcoholism and Related Conditions. Archives of General Psychiatry, 62, 1079-1106.

Hattie, J. A., Myers, J. E., \& Sweeney, T. J. (2004). A factor structure of wellness: Theory, assessment, analysis, and practice. Journal of Counseling o Development, 82, 354-364.

Henderson, K. V., Goldsmith, R. E., \& Flynn, L. R. (1995). Demographic characteristics of subjective age. The Journal of Social Psychology, 135, 447-458.

Hong, S. M., \& Giannakopoulos, E. (1994). The relationship of satisfaction with life to personality characteristics. Journal of Psychology, 128, 547-558.

Howell, L. C. (2001). Implications of personal values in women's midlife development. Counseling and Values, 46, 54-65.

Hummert, M. L., Garstka, T. A., O’Brien, L. T., Greenwald, A. G., \& Mellott, D. S. (2002). Using the Implicit Association Test to measure age differences in implicit social cognitions. Psychology \& Aging, 17, 482-495.

Lachman, M. E. (2001). Handbook of midlife development. New York: Wiley.

Levinson, D. J., \& Levinson, J. (1996). The seasons of a woman's life. New York: Ballantine Books.

MacPherson, K. L. (1995). Going to the source: Women reclaim menopause. Feminist Studies, 21, 347-357.

Markson, E. W., \& Taylor, C. A. (2000). The mirror has two faces. Ageing and Society, 20, 137-160.

McIntosh, C. N. (2001). Report on the construct validity of the Temporal Satisfaction With Life Scale. Social Indicators Research, 54, 37-56.

McQuaide, S. (1998). Discontent at midlife: Issues and considerations in working toward women's well-being. Families in Society: The Journal of Contemporary Human Services, 79, 532-542.

Montepare, J. M., \& Lachman, M. E. (1989). "You're only as old as you feel": Self-perceptions of age, fears of aging, and life satisfaction from adolescence to old age. Psychology of Aging, 4, 73-78.

Myers, J. E. (2005). Wellness in later life: Research implications. In J. E. Myers \& T. J. Sweeney (Eds.), Wellness in counseling: Theory, research, and practice (pp. 99-104). Alexandria, VA: American Counseling Association.

Myers, J. E., \& Sweeney, T. J. (1999, 2005). Manual for the Five Factor Wellness Inventory. Greensboro, NC: Authors.

Myers, J. E., \& Sweeney, T. J. (Eds.). (2005). Wellness in counseling: Theory, research, and practice. Alexandria, VA: American Counseling Association.

Myers, J. E., Sweeney, T. J., \& Witmer, J. M. (2000). The Wheel of Wellness counseling for wellness: A holistic model for treatment planning. Journal of Counseling \& Development, 78, 251-266.

Palmore, E. (1981). Social patterns in normal aging: Findings from the Duke longitudinal study. Durham, NC: Duke University Press.

Pavot, W., \& Diener, E. (1993). Review of the Satisfaction With Life Scale. Psychological Assessment, 5 , 164-172.

Pinquart, M., \& Sorensen, S. (2001). Gender differences in self-concept and psychological well-being in old age: A meta-analysis. Journal of Gerontology, 56, 195-213.

Rodin, J., \& Ickovics, J. R. (1990). Women's health: Review and research agenda as we approach the 21 st century. American Psychologist, 44, 1394-1401.

Ryff, C. D. (1989). In the eye of the beholder: Views of psychological well-being among middle-aged and older adults. Psychology of Aging, 4, 195-210.

Ryff, C. D., \& Keyes, C. L. M. (1995). The structure of psychological well-being revisited. Journal of Personality and Social Psychology, 69, 719-727.

Saucier, M. G. (2004). Midlife and beyond: Issues for aging women. Journal of Counseling \& Development, 82, 420-425.

Scheffé, H. (1959). The analysis of variance. New York: Wiley.

Seccombe, K., \& Ishii-Kuntz, M. (1991). Perceptions of problems associated with aging: Comparisons across four elder age cohorts. The Gerontologist, 31, 527-533.

Sheehy, G. (2006). Sex and the seasoned woman. New York: Random House.

Steverink, N., Westerhof, G. J., Bode, C., \& Dittmann-Kohli, F. (2001). The personal experience of aging, individual resources, and subjective well-being. Journals of Gerontology Series B: Psychological Sciences \& Social Sciences, 56B, 364-373.

Uotinen, V., Rantanen, T., \& Suutama, T. (2005). Perceived age as a predictor of old age mortality: A 13-year prospective study. Age \& Ageing, 34, 368-372. 
U.S. Bureau of the Census. (2001). Age 2000. Washington, DC: U.S. Government Printing Office.

Waskel, S. A., \& Phelps, L. H. (1995). Women ages 30-60 and their crisis events. Psychological Reports, 77, 1211-1217.

Wethington, K., Kessler, R. C., \& Pixley, J. E. (2004). Psychological turning points and the "midlife crisis." In O. G. Brim, C. D. Ryff, \& R. C. Kessler (Eds.), How healthy are we? A national study of well-being at midlife. Chicago: University of Chicago Press.

Wilkes, R. E. (1992). A structural modeling approach to the measurement and meaning of cognitive age. Journal of Consumer Research, 19, 292-301.

Wilson, W. (1967). Correlates of avowed happiness. Psychological Bulletin, 67, 294-306. 